\title{
HEPARINIZATION ON PERICARDIAL SUBSTITUTES CAN REDUCE ADHESION AND EPICARDIAL INFLAMMATION IN THE DOG
}

Jen-Her Lu, MD, PhD

Yen Chang, MD

Hsing-Wen Sung, PhD

Yung-Tang Chiu, DVM, PhD

Ping-Cheng Yang, DVM, PhD

Betau Hwang, MD
Objective: Primary concerns about currently available pericardial substitutes include adhesion and epicardial reaction. The purpose of this study is to evaluate host reaction to pericardial substitutes with and without incorporating slow heparin release. Methods: To avoid biologic variation among these pericardial patches, we made a composite of six membranes. The composite membrane consisted of epoxy-fixed patches with (1) or without (2) ionically bound heparin, a glutaraldehyde-fixed patch with (3) or without (4) ionically bound heparin, an expanded polytetrafluoroethylene patch (5), and a polyester polymeric patch (6). Ten recipient dogs weighing from 12 to $19 \mathrm{~kg}$ (mean $13.6 \mathrm{~kg}$ ) were used to assess the composite membranes as pericardial substitutes. The implanted composite membranes were retrieved 1 week (one $\operatorname{dog}$ ), 2 weeks (one $\operatorname{dog}$ ), 4 weeks (one dog), 8 weeks (one dog), and 12 weeks (six dogs) after implantation. Results: Overall, the synthetic patches had a more notable inflammatory reaction than the biologic patches with or without ionically bound heparin. The heparin-bound patches caused significantly less inflammation than their nonheparinized counterparts. The heparinized porcine patches crosslinked with different compounds were found to have less fibrous formation than the nonheparinized patches and the synthetic patches. Conclusions: Heparinized pericardial substitutes may cause less adhesion and inflammatory reaction than nonheparinized material. (J Thorac Cardiovasc Surg 1998;115:1111-20)
P rimary closure of the pericardium is recommended because it is believed to reduce the formation of mediastinal adhesion and postoperative complications. The use of pericardial substitutes is advocated when primary closure is not possible. Several materials can be used as pericardial substitutes, including fascia lata, ${ }^{1}$ silicone rubber, ${ }^{2-4}$ rubber-coated Dacron ${ }^{2}$ or polyester polymer, ${ }^{5}$ and polytetrafluoroethylene (PTFE), ${ }^{2}$ as well as mammalian pericardium. ${ }^{6-11}$ These materials have been tested in

From the Section of Pediatric Cardiology and Cardiovascular Surgery, Veterans General Hospital, Taipei, the Department of Chemical Engineering, National Central University, and the Department of Pathology, Pig Research Institute, Taipei, Taiwan.

Received for publication Dec. 24, 1996; revisions requested April 15, 1997; revisions received Sept. 24, 1997; accepted for publication Sept. 30, 1997.

Address for reprints: Jen-Her Lu, MD, Section of Pediatric Cardiology, Veterans General Hospital, Taipei, Taiwan.

Copyright (C) 1998 by Mosby, Inc.

$0022-5223 / 98 \$ 5.00+0 \quad \mathbf{1 2 / 1 / 8 6 5 1 5}$ the past to facilitate reoperations, with inconclusive results.

The primary concerns about currently available pericardial substitutes include adhesion and epicardial reaction. The synthetic patches, made from expanded PTFE (ePTFE) or polyester polymer (Dacron), are widely used as pericardial substitutes. Several groups ${ }^{2-6}$ reported the presence of a tissuefree space around the synthetic patch that facilitates the opening of the chest and diminishes damage to the heart. However, the synthetic patch brought on severe inflammatory reaction and diffuse fibrosis. The epicardium beneath the synthetic patch became covered by a dense layer of fibrotic tissue. In a canine model, Meus and associates ${ }^{5}$ reported that recognition of the coronary artery was greatly impeded by this fibrotic tissue, which was very difficult to separate from the underlying myocardium and vessels. The glutaraldehyde-fixed patches, made from heterologous porcine, ${ }^{5,6}$ equine, ${ }^{7,8}$ and bovine pericardium, ${ }^{9-11}$ were often used as pericardial substitutes. However, glutaraldehyde tended to stiffen biologic tissue and enhance fibrosis, adhesion, and 
Table I. Macroscopic assessment of the retrieved pericardial substitutes

\begin{tabular}{|c|c|c|}
\hline \multirow[t]{3}{*}{ Pliability } & $\mathrm{P} 0$ & Patch appeared soft and pliable \\
\hline & P1 & $\begin{array}{l}\text { Patch appeared less pliable without } \\
\text { thickening }\end{array}$ \\
\hline & $\mathrm{P} 2$ & $\begin{array}{l}\text { Patch appeared less pliable and } \\
\text { thickened }\end{array}$ \\
\hline \multirow[t]{6}{*}{ Adhesion } & M0 & No adhesion \\
\hline & M1 & $\begin{array}{l}\text { Scanty adhesion, which can be } \\
\text { peeled off easily }\end{array}$ \\
\hline & M2 & $\begin{array}{l}\text { Mild adhesion; gentle dissection } \\
\text { required for separation }\end{array}$ \\
\hline & M3 & $\begin{array}{l}\text { Moderate adhesion; aggressive dis- } \\
\text { section required for separation }\end{array}$ \\
\hline & M4 & $\begin{array}{l}\text { Dense adhesion; sharp dissection } \\
\text { required for separation }\end{array}$ \\
\hline & M5 & $\begin{array}{l}\text { Dense adhesion; cannot be sepa- } \\
\text { rated }\end{array}$ \\
\hline \multirow{4}{*}{$\begin{array}{l}\text { Epicardial/pleural } \\
\text { reaction }\end{array}$} & E0 & No fibrosis \\
\hline & E1 & $\begin{array}{l}\text { Trivial fibrotic layer; the underlying } \\
\text { structures were easily identifiable }\end{array}$ \\
\hline & E2 & $\begin{array}{l}\text { Dense fibrotic tissue layer; the rec- } \\
\text { ognition of underlying structures } \\
\text { was severely impeded }\end{array}$ \\
\hline & E3 & $\begin{array}{l}\text { Dense fibrotic tissue layer; the un- } \\
\text { derlying structures were not } \\
\text { identifiable }\end{array}$ \\
\hline
\end{tabular}

calcification. ${ }^{11}$ To address the aforementioned deficiencies, a cross-linking technique using an epoxy compound as a fixative has recently been developed. ${ }^{12,13}$ Furthermore, heparinization of biomaterials to enhance the antithrombogenicity is now recognized as a decisive factor in the development of antiadhesive membranes. ${ }^{14}$ The purpose of this study was to evaluate host reaction to pericardial substitute with and without incorporating slow heparin release. In addition, two commercially available synthetic pericardial substitutes (ePTFE and polyester polymeric patch) were used as controls.

\section{Methods}

Pericardium harvesting. Fresh porcine pericardia procured from a slaughterhouse were used as the raw materials. The procured porcine pericardia were transported in cold physiologic saline solution. On return, the pericardia were first gently rinsed with fresh saline solution to rid them of excess blood on the tissue. Adherent fat was then carefully trimmed from the pericardial surface. The maximum time period between retrieval and initiation of tissue fixation was less than 10 hours.

Fixation process. For the epoxy-fixed pericardial patches without ionically bound heparin, the porcine pericardia were first fixed in an epoxy compound solution (ethylene glycol diglycidyl ether, Denacol EX-810, Nagase Chemicals, Ltd., Osaka, Japan) at room temperature for 6
Table II. Microscopic assessment of the retrieved pericardial substitutes

\begin{tabular}{|c|c|c|}
\hline \multirow{4}{*}{$\begin{array}{l}\text { Acute inflammatory } \\
\text { reaction }\end{array}$} & A0 & Nil \\
\hline & A1 & $\begin{array}{l}\text { Sparse focal neutrophils and } \\
\text { plasma cell infiltration }\end{array}$ \\
\hline & $\mathrm{A} 2$ & $\begin{array}{l}\text { Focal aggregates of neuro- } \\
\text { philes, plasma cells }\end{array}$ \\
\hline & $\mathrm{A} 3$ & $\begin{array}{l}\text { Diffuse aggregates of neu- } \\
\text { trophils }\end{array}$ \\
\hline \multirow{6}{*}{$\begin{array}{l}\text { Chronic inflammatory } \\
\text { reaction }\end{array}$} & $\mathrm{C} 0$ & Nil \\
\hline & $\mathrm{C} 1$ & $\begin{array}{l}\text { Sparse plasma cells and lym- } \\
\text { phocytes }\end{array}$ \\
\hline & $\mathrm{C} 2$ & $\begin{array}{l}\text { Focal aggregates of plasma } \\
\text { cells and lymphocytes }\end{array}$ \\
\hline & $\mathrm{C} 3$ & $\begin{array}{l}\text { Diffuse lymphocytic aggre- } \\
\text { gates in whole layers }\end{array}$ \\
\hline & $\mathrm{C} 4$ & $\begin{array}{l}\text { Diffuse lymphocytic aggre- } \\
\text { gates extending across the } \\
\text { patch }\end{array}$ \\
\hline & $\mathrm{C} 5$ & $\begin{array}{l}\text { Extensive lymphocytic aggre- } \\
\text { gates with necrotic cells }\end{array}$ \\
\hline \multirow{6}{*}{$\begin{array}{l}\text { Fibrous reaction } \\
\text { (histologic findings) }\end{array}$} & F0 & No fibrous reaction \\
\hline & $\mathrm{F} 1$ & $\begin{array}{l}\text { Minimal fibrous reaction } \\
\text { with trivial fibrin deposit }\end{array}$ \\
\hline & $\mathrm{F} 2$ & $\begin{array}{l}\text { Sparse focal fibrous connec- } \\
\text { tive tissue, hyalinization, } \\
\text { fibrin deposit }\end{array}$ \\
\hline & F3 & $\begin{array}{l}\text { A thin layer of fibrous con- } \\
\text { nective tissue, hyaliniza- } \\
\text { tion, fibrin deposit }\end{array}$ \\
\hline & F4 & $\begin{array}{l}\text { A thick layer of fibrous con- } \\
\text { nective tissue, hyaliniza- } \\
\text { tion, without evidence of } \\
\text { fibrous ingrowth }\end{array}$ \\
\hline & F5 & $\begin{array}{l}\text { Dense fibrous connective } \\
\text { tissue, diffuse ingrowth of } \\
\text { native collagen between } \\
\text { patch and underlying } \\
\text { structures }\end{array}$ \\
\hline
\end{tabular}

days. The solution was buffered with sodium carbonate/ sodium bicarbonate $(0.21 / 0.02 \mathrm{~mol} / \mathrm{L}, \mathrm{pH} 10.5)$. The amount of solution used in fixation was approximately 200 $\mathrm{ml}$ for a $6 \times 6 \mathrm{~cm}$ piece of pericardium. The fixed porcine pericardia were subsequently sterilized with the same epoxy compound solution ( $2 \%$ ) at $37^{\circ} \mathrm{C}$ for 7 days.

For the epoxy-fixed pericardial patches with ionically bound heparin, the fresh porcine pericardia were first immersed in a $1 \%$ protamine sulfate solution for 1 hour. The porcine pericardia were then fixed in the epoxy compound solution as described at room temperature for 6 days. Finally, the fixed pericardia were heparinized in a $0.5 \%$ sodium heparin solution (from porcine intestinal mucosa, Sigma Chemical Co., St. Louis, Mo.) at $37^{\circ} \mathrm{C}$ for 1 hour. The same sterilization procedure as used for the epoxy-fixed patch without ionically bound heparin was applied.

For the glutaraldehyde-fixed pericardial patches without ionically bound heparin, the fresh porcine pericardia 
Table III. Macroscopic evaluation of patch retrieved at 1, 2, 4, 8, or 12 weeks of implantation

\begin{tabular}{|c|c|c|c|c|c|c|}
\hline \multirow{3}{*}{$\begin{array}{l}\text { Time } \\
\text { (wks) }\end{array}$} & \multicolumn{6}{|c|}{ Grades of pliability/adhesion/epicardial reaction: epicardial side of patch } \\
\hline & \multicolumn{2}{|c|}{ Epoxy-fixed } & \multicolumn{2}{|c|}{ GA-fixed } & \multirow[b]{2}{*}{ ePTFE } & \multirow[b]{2}{*}{ Polyester } \\
\hline & $w-H$ & $w / o-H$ & $w-H$ & $w / o-H$ & & \\
\hline $1(n=1)$ & P0M0E0 & P0M0E0 & P0M0E0 & P0M0E0 & P1M0E0 & P1M0E0 \\
\hline $2(n=1)$ & P0M0E0 & P0M3E0 & P0M0E0 & P0M3E1 & P1M0E1 & P2M3E3 \\
\hline $4(n=1)$ & P0M0E1 & P1M3E1 & P1M1E1 & P1M2E1 & P1M0E2 & P2M4E3 \\
\hline $8(n=1)$ & P1M2E1 & P1M3E1 & P1M2E1 & P1M2E2 & P1M0E2 & P2M4E3 \\
\hline \multirow[t]{3}{*}{$12(n=6)$} & $\mathrm{P}=0.8 \pm 0.2$ & $\mathrm{P}=1.3 \pm 0.2$ & $P=1.0 \pm 0.4$ & $P=1.4 \pm 0.6$ & $\mathrm{P}=1.0 \pm 0.0$ & $\mathrm{P}=2.0 \pm 0.0$ \\
\hline & $\mathrm{M}=2.8 \pm 0.9$ & $\mathrm{M}=4.5 \pm 0.5$ & $\mathrm{M}=3.2 \pm 0.4$ & $\mathrm{M}=4.3 \pm 0.5$ & $\mathrm{M}=0.0 \pm 0.0$ & $\mathrm{M}=5.0 \pm 0.0$ \\
\hline & $\mathrm{E}=1.0 \pm 0.0$ & $\mathrm{E}=1.6 \pm 0.4$ & $\mathrm{E}=1.0 \pm 0.0$ & $E=1.8 \pm 0.4$ & $\mathrm{E}=2.6 \pm 0.0$ & $\mathrm{E}=3.0 \pm 0.0$ \\
\hline
\end{tabular}

$w$ - $H$, With ionically bound heparin patch; w/o-H, without ionically bound heparin patch; GA-fixed, Glutaraldehyde-fixed patch; $e P T F E$, expanded polytetrafluoroethylene patch; Polyester, polyester patch (Dacron); $P$, pliability; $M$, adhesion; $E$, epicardial reaction.

Table IV. Macroscopic evaluation of patch retrieved at 1, 2, 4, 8, or 12 weeks of implantation

\begin{tabular}{|c|c|c|c|c|c|c|}
\hline \multirow[b]{3}{*}{ Time $(w k)$} & \multicolumn{6}{|c|}{ Grades of adhesion and pleural reaction: pleural side of patch } \\
\hline & \multicolumn{2}{|c|}{ Epoxy-fixed } & \multicolumn{2}{|c|}{ GA-fixed } & \multirow[b]{2}{*}{ ePTFE } & \multirow[b]{2}{*}{ Polyester } \\
\hline & $w-H$ & $w / o-H$ & $w-H$ & $w / o-H$ & & \\
\hline $1(n=1)$ & M0E0 & M0E0 & M0E0 & M0E0 & M0E0 & M0E0 \\
\hline $2(n=1)$ & M0E1 & M3E1 & M0E0 & M3E1 & M0E2 & M3E2 \\
\hline $4(n=1)$ & M1E1 & M3E1 & M2E0 & M2E1 & M0E2 & M4E3 \\
\hline $8(n=1)$ & M2E1 & M3E2 & M2E1 & M3E1 & M0E2 & M5E3 \\
\hline $12(n=6)$ & $\mathrm{M}=2.6 \pm 0.3$ & $\mathrm{M}=4.0 \pm 0.5$ & $\mathrm{M}=2.8 \pm 0.2$ & $\mathrm{M}=4.4 \pm 0.4$ & $\mathrm{M}=0.0 \pm 0.0$ & $\mathrm{M}=5.0 \pm 0.0$ \\
\hline & $\mathrm{E}=0.8 \pm 0.4$ & $\mathrm{E}=1.8 \pm 0.4$ & $\mathrm{E}=1.2 \pm 0.4$ & $\mathrm{E}=2.0 \pm 0.6$ & $\mathrm{E}=3.0 \pm 0.0$ & $\mathrm{E}=3.0 \pm 0.0$ \\
\hline
\end{tabular}

$w$ - $H$, With ionically bound heparin patch; w/o-H, without ionically bound heparin patch; GA-fixed, glutaraldehyde-fixed patch; ePTFE, expanded polytetrafluoroethylene patch; Polyester, polyester patch (Dacron); $M$, adhesion; E, pleural reaction.

were first fixed in a $0.625 \%$ glutaraldehyde solution at room temperature for 10 hours. The solution was buffered with HEPES buffer (0.02 mol/L, pH 7.4). Subsequently, the fixed pericardia were sterilized in a glutaraldehydebased sterilant in a phosphate buffer at $45^{\circ} \mathrm{C}$ for 2 days. The heparinization process for the glutaraldehyde-fixed pericardial patches with ionically bound heparin was similar to that for their epoxy-fixed counterparts: the impregnation of protamine and heparinization were performed just before and after glutaraldehyde fixation, respectively.

Composite membranes as pericardial substitutes. To avoid biologic variation among these pericardial patches, we used a composite membrane. Preparation of the composite patches was completed by suturing these patches with 6-0 polypropylene sutures in the following order: (1) an epoxy-fixed patch with ionically bound heparin, (2) a glutaraldehyde-fixed patch with ionically bound heparin, (3) an ePTFE patch,* (4) a polyester polymeric patch (Cooley low porosity polyester fabric, Meadox Medicals, Inc., Oakland, N.J.), (5) an epoxy-fixed patch without ionically bound heparin, and (6) a glutaraldehyde-fixed patch without ionically bound heparin. Each individual patch was $3 \mathrm{~cm}$ in length and $1 \mathrm{~cm}$ in width, which made a $3 \mathrm{~cm} \times 6 \mathrm{~cm}$ composite membrane. Care was taken to ensure that the smooth side of this biologic

* Gore-Tex surgical membrane, W. L. Gore \& Associates, Inc., Flagstaff, Ariz, patch was in contact with the epicardial surface of the recipient hearts.

Surgery. Ten recipient dogs weighing from 12 to $19 \mathrm{~kg}$ (mean $13.6 \mathrm{~kg}$ ) were used to assess the composite membranes. An intravenous line, an arterial line in the femoral artery, and an electrocardiographic monitor were established. Anesthesia was induced via the external jugular vein with $2.5 \%$ thiamylal sodium (Surital) at a dose of 17.5 $\mathrm{mg} / \mathrm{kg}$. Anesthesia was maintained in the operating room with halothane and nitrous oxide in oxygen. Mechanical ventilation was instituted with an approximate tidal volume set at $10 \mathrm{ml} / \mathrm{kg}$ body weight with $100 \%$ oxygen at a rate of 8 to 14 cycles per minute. Anesthesia was maintained at stage III, planes 1 to 2 , with a mixture of halothane in oxygen. Ventilation rates were adjusted to maintain arterial blood gases in the normal physiologic range.

The heart was exposed via a left lateral thoracotomy incision through the fourth intercostal space. A $2 \times 5 \mathrm{~cm}$ segment of the midportion of the pericardium was removed and the composite patch was anchored to the pericardial defect with 6-0 Prolene interrupted sutures (Ethicon, Inc., Somerville, N.J.). Care was taken to avoid contact with the epicardial surface of the heart. Prophylactic antibiotics were given intravenously just before and after the operation and were administered intramuscularly for 5 days after the operation. Animal care was in compliance with the "Principles of Laboratory Animal Care" formulated by the National Society for Medical 

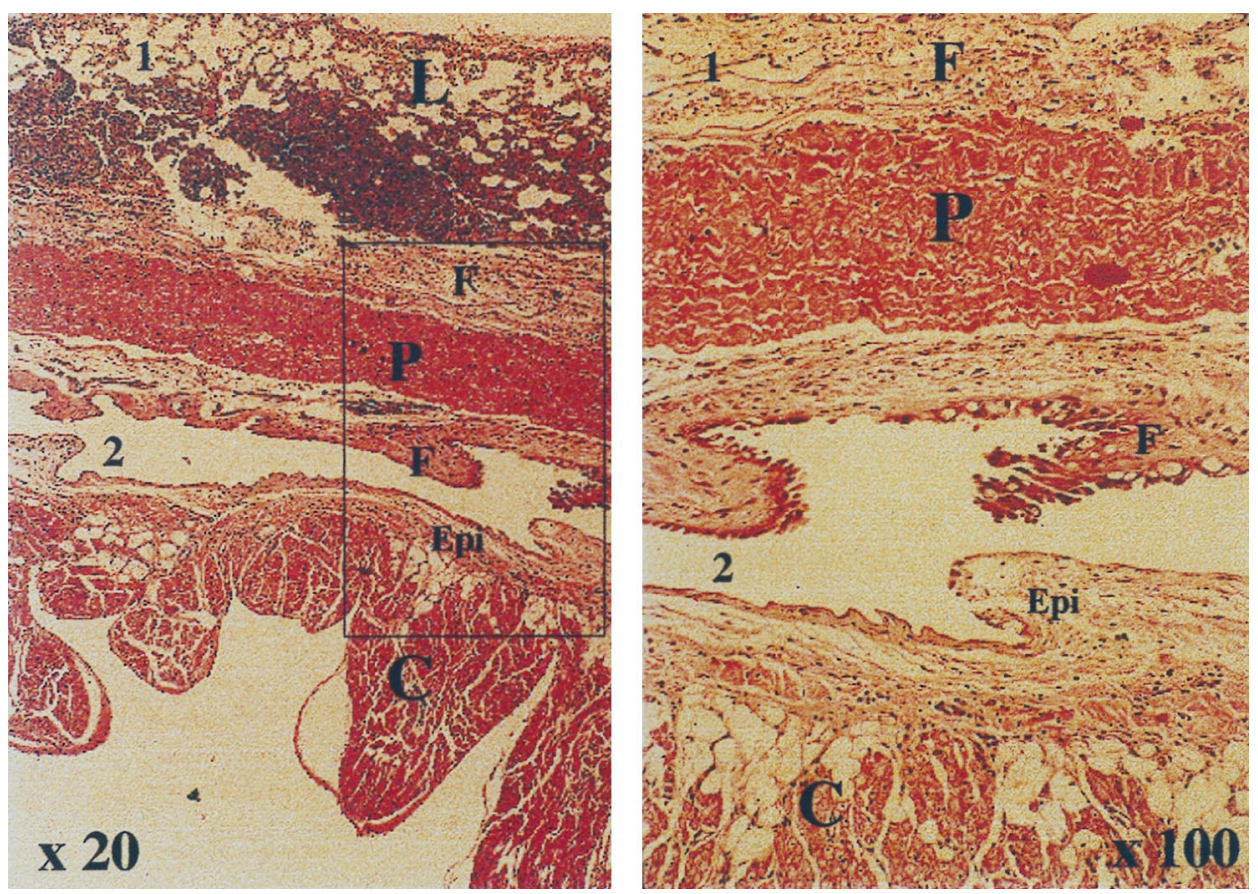

Fig. 1. The epoxy-fixed patch with ionically bound heparin retrieved 12 weeks after implantation; stain: hematoxylin-eosin. Left, Light micrograph showed focal fibrosis, a scattering of hemorrhagic infiltrations, and occasional lymphocytes and plasma cells. The thin layer of fibrous tissue $(F)$ covered the intact patch $(P)$ and the myocardium $(C)(\times 20)$. Right, The pleural side of the patch showed fibrous reactive zone $(F)$ over the lung. The epicardial side (epi) of the patch was clear with minimal epicardial fibrous reaction $(F)$ $(\times 100)$.

Table V. Microscopic evaluation of patch retrieved at 1, 2, 4, 8, or 12 weeks of implantation

\begin{tabular}{|c|c|c|c|c|c|c|}
\hline \multirow[b]{3}{*}{ Time (wk) } & \multicolumn{6}{|c|}{ Grades of inflammatory and fibrous reaction: epicardial side of patch } \\
\hline & \multicolumn{2}{|c|}{ Epoxy-fixed } & \multicolumn{2}{|c|}{ GA-fixed } & \multirow[b]{2}{*}{ ePTFE } & \multirow[b]{2}{*}{ Polyester } \\
\hline & $w-H$ & $w / o-H$ & $w-H$ & $w / o-H$ & & \\
\hline $1(n=1)$ & $\mathrm{A} 1 \mathrm{C} 0 \mathrm{~F} 0$ & $\mathrm{~A} 2 \mathrm{C} 0 \mathrm{~F} 0$ & $\mathrm{~A} 2 \mathrm{C} 0 \mathrm{~F} 0$ & $\mathrm{~A} 2 \mathrm{C} 0 \mathrm{~F} 0$ & $\mathrm{~A} 3 \mathrm{C} 0 \mathrm{~F} 0$ & $\mathrm{~A} 3 \mathrm{C} 0 \mathrm{~F} 0$ \\
\hline $2(n=1)$ & $\mathrm{A} 1 \mathrm{C} 0 \mathrm{~F} 1$ & $\mathrm{~A} 3 \mathrm{C} 0 \mathrm{~F} 1$ & $\mathrm{~A} 2 \mathrm{C} 0 \mathrm{~F} 0$ & $\mathrm{~A} 3 \mathrm{C} 0 \mathrm{~F} 1$ & $\mathrm{~A} 3 \mathrm{C} 0 \mathrm{~F} 1$ & $\mathrm{~A} 4 \mathrm{C} 0 \mathrm{~F} 3$ \\
\hline $4(n=1)$ & $\mathrm{A} 1 \mathrm{C} 1 \mathrm{~F} 3$ & $\mathrm{~A} 2 \mathrm{C} 2 \mathrm{~F} 2$ & $\mathrm{~A} 1 \mathrm{C} 1 \mathrm{~F} 0$ & $\mathrm{~A} 1 \mathrm{C} 1 \mathrm{~F} 2$ & $\mathrm{~A} 3 \mathrm{C} 1 \mathrm{~F} 3$ & $\mathrm{~A} 3 \mathrm{C} 4 \mathrm{~F} 3$ \\
\hline $8(n=1)$ & A1C1F3 & $\mathrm{A} 2 \mathrm{C} 2 \mathrm{~F} 4$ & $\mathrm{~A} 1 \mathrm{C} 2 \mathrm{~F} 2$ & A1C2F4 & $\mathrm{A} 2 \mathrm{C} 2 \mathrm{~F} 4$ & A2C4F5 \\
\hline \multirow[t]{3}{*}{$12(n=6)$} & $\mathrm{A}=1.0 \pm 0.2$ & $\mathrm{~A}=2.3 \pm 0.4$ & $\mathrm{~A}=1.2 \pm 0.3$ & $\mathrm{~A}=2.6 \pm 0.7$ & $\mathrm{~A}=1.6 \pm 0.3$ & $\mathrm{~A}=2.0 \pm 0.2$ \\
\hline & $\mathrm{C}=2.0 \pm 0.0$ & $\mathrm{C}=2.2 \pm 0.3$ & $\mathrm{C}=2.2 \pm 0.4$ & $\mathrm{C}=2.2 \pm 0.4$ & $\mathrm{C}=2.2 \pm 0.4$ & $\mathrm{C}=4.2 \pm 0.4$ \\
\hline & $\mathrm{F}=2.8 \pm 0.3$ & $\mathrm{~F}=3.8 \pm 0.2$ & $\mathrm{~F}=3.0 \pm 0.2$ & $\mathrm{~F}=4.0 \pm 0.0$ & $\mathrm{~F}=4.0 \pm 0.0$ & $\mathrm{~F}=5.0 \pm 0.0$ \\
\hline
\end{tabular}

$\overline{w-H}$, With ionically bound heparin patch; w/o-H, without ionically bound heparin patch; GA-fixed, glutaraldehyde-fixed patch; $e P T F E$, expanded polytetrafluoroethylene patch; Polyester, polyester patch (Dacron); $A$, acute inflammatory reaction; $C$, chronic inflammatory reaction; $F$, fibrous reaction (histology).

Research and the "Guide for the Care and Use of Laboratory Animals" prepared by the Institute of Laboratory Animal Resources and published by the National Institutes of Health (NIH Publication No. 86-23, revised 1985).

Pathologic examination. The implanted composite membranes were retrieved at the end of 1 week (one dog), 2 weeks (one dog), 4 weeks (one dog), 8 weeks (one dog), and 12 weeks (six dogs) after the operation. The en bloc heart, including pericardium and left lung, was removed through a left-sided thoracotomy. The retrieved composite membranes were then examined and photographed. The development of adhesions and the epicardial reaction were graded (Table I). Subsequently, the retrieved patches were fixed in $10 \%$ phosphate-buffered formalin for at least 3 days. Histologic specimens of the patches, suture lines, and epicardia were obtained. All specimens for histologic examination, including the samples taken after harvesting, were embedded in paraffin, sectioned at $5 \mu \mathrm{m}$, and stained 

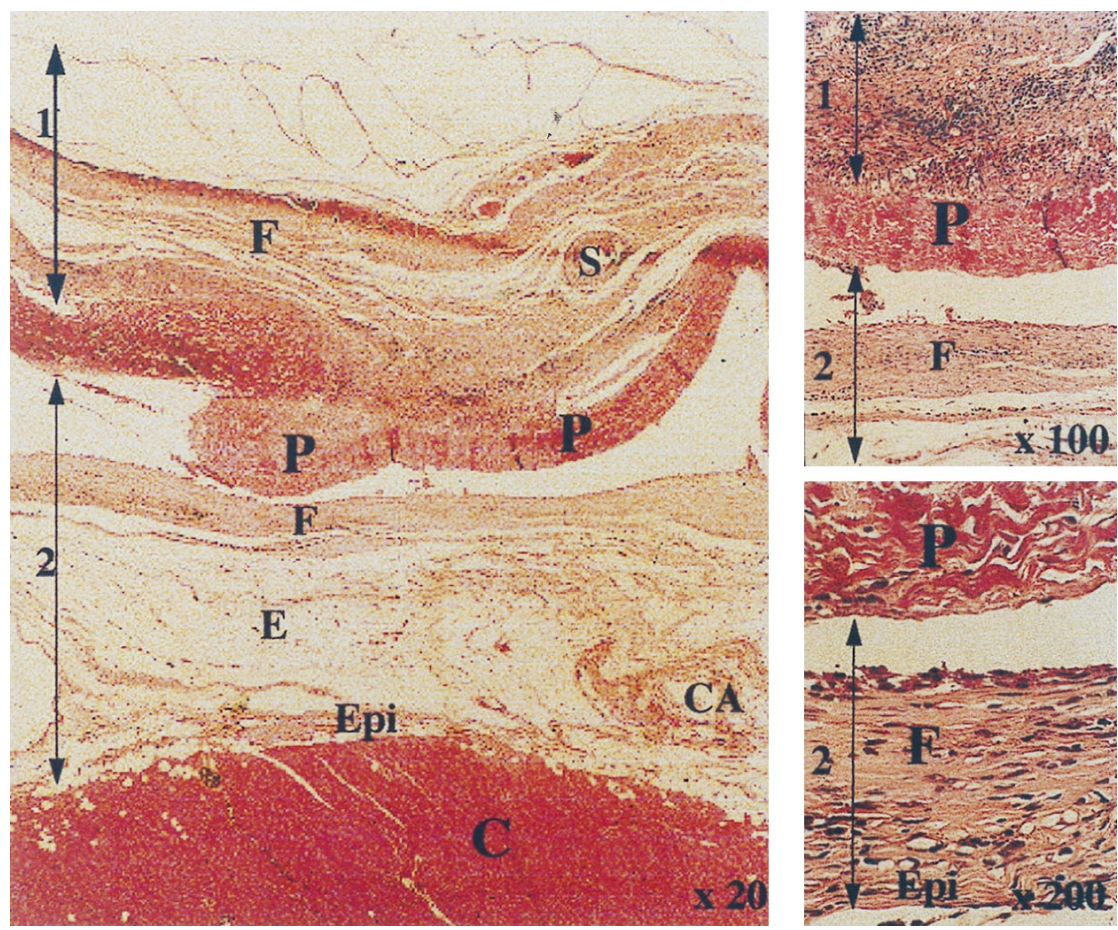

Fig. 2. The epoxy-fixed patch without ionically bound heparin retrieved 12 weeks after implantation; stain: hematoxylin-eosin. Left, Cross section on the surface of the heart. Light micrograph showed dense collagenous fibrosa $(F)$ with strongly folded surface. The epicardial inflammatory zone $(2)$ of the patch $(P)$ was covered with fibrous tissue $(F)$ with edematous reaction $(E)(\times 20)$. Top right, The inflammatory zone of pleural side (1) of the patch showed dense fibrous tissue. Light micrograph showed focal fibrosis, diffused infiltration of lymphocytes, and plasma cells through epicardial layers $(2)(\times 100)$. Bottom right, Patch appeared soft and pliable. The epicardial fibrosis $(F)$ could be peeled off easily $(\times 200)$. $C A$, Coronary artery; $S$, suture.

Table VI. Microscopic evaluation of patch retrieved at 1, 2, 4, 8, or 12 weeks of implantation

\begin{tabular}{|c|c|c|c|c|c|c|}
\hline \multirow[b]{3}{*}{ Time (wk) } & \multicolumn{6}{|c|}{ Grades of inflammatory and fibrous reaction: Pleural side of patch } \\
\hline & \multicolumn{2}{|c|}{ Epoxy-fixed } & \multicolumn{2}{|c|}{ GA-fixed } & \multirow[b]{2}{*}{ ePTFE } & \multirow[b]{2}{*}{ Polyester } \\
\hline & $w-H$ & $w / o-H$ & $w-H$ & $w / o-H$ & & \\
\hline $1(n=1)$ & $\mathrm{A} 1 \mathrm{C} 0 \mathrm{~F} 0$ & $\mathrm{~A} 2 \mathrm{C} 0 \mathrm{~F} 0$ & $\mathrm{~A} 2 \mathrm{C} 0 \mathrm{~F} 0$ & $\mathrm{~A} 2 \mathrm{C} 0 \mathrm{~F} 0$ & $\mathrm{~A} 3 \mathrm{C} 0 \mathrm{~F} 0$ & $\mathrm{~A} 3 \mathrm{C} 0 \mathrm{~F} 0$ \\
\hline $2(n=1)$ & $\mathrm{A} 2 \mathrm{C} 0 \mathrm{~F} 2$ & $\mathrm{~A} 3 \mathrm{C} 1 \mathrm{~F} 3$ & $\mathrm{~A} 3 \mathrm{C} 0 \mathrm{~F} 3$ & $\mathrm{~A} 3 \mathrm{C} 1 \mathrm{~F} 2$ & $\mathrm{~A} 3 \mathrm{C} 1 \mathrm{~F} 4$ & $\mathrm{~A} 3 \mathrm{C} 2 \mathrm{~F} 4$ \\
\hline $4(n=1)$ & $\mathrm{A} 1 \mathrm{C} 1 \mathrm{~F} 1$ & $\mathrm{~A} 3 \mathrm{C} 4 \mathrm{~F} 3$ & $\mathrm{~A} 2 \mathrm{C} 2 \mathrm{~F} 3$ & $\mathrm{~A} 2 \mathrm{C} 4 \mathrm{~F} 2$ & $\mathrm{~A} 2 \mathrm{C} 2 \mathrm{~F} 4$ & A2C5F5 \\
\hline $8(n=1)$ & $\mathrm{A} 1 \mathrm{C} 2 \mathrm{~F} 4$ & $\mathrm{~A} 2 \mathrm{C} 3 \mathrm{~F} 4$ & $\mathrm{~A} 1 \mathrm{C} 3 \mathrm{~F} 2$ & $\mathrm{~A} 2 \mathrm{C} 3 \mathrm{~F} 3$ & $\mathrm{~A} 2 \mathrm{C} 2 \mathrm{~F} 4$ & A2C5F5 \\
\hline \multirow[t]{3}{*}{$12(n=6)$} & $\mathrm{A}=1.2 \pm 0.1$ & $\mathrm{~A}=1.6 \pm 0.4$ & $\mathrm{~A}=1.0 \pm 0.3$ & $\mathrm{~A}=1.4 \pm 0.2$ & $\mathrm{~A}=2.6 \pm 0.4$ & $\mathrm{~A}=2.2 \pm 0.2$ \\
\hline & $\mathrm{C}=2.2 \pm 0.4$ & $\mathrm{C}=3.2 \pm 0.2$ & $C=2.6 \pm 0.4$ & $\mathrm{C}=3.4 \pm 0.4$ & $\mathrm{C}=2.2 \pm 0.3$ & $\mathrm{C}=5.0 \pm 0.0$ \\
\hline & $F=2.6 \pm 0.6$ & $F=4.0 \pm 0.0$ & $F=2.5 \pm 0.2$ & $\mathrm{~F}=4.0 \pm 0.0$ & $\mathrm{~F}=3.4 \pm 0.0$ & $\mathrm{~F}=5.0 \pm 0.0$ \\
\hline
\end{tabular}

$w$ - $H$, With ionically bound heparin patch; w/o-H, without ionically bound heparin patch; $G A$-fixed, glutaraldehyde-fixed patch; ePTFE, expanded polytetrafluoroethylene patch; Polyester, polyester patch (Dacron); $A$, acute inflammatory reaction; $C$, chronic inflammatory reaction; $F$, fibrous reaction.

with hematoxylin-eosin. All biologic patches were stained with van Gieson technique additionally to demonstrate the collagen component. A system of assessing the microscopic status of the individual patches by assigning them arbitrary scores was devised and is described in Table II.

\section{Results}

All the animals survived implantation and were evaluated as scheduled. From the sequential observation of the specimens, the epicardial and pleural reactions to the patch could be classified 

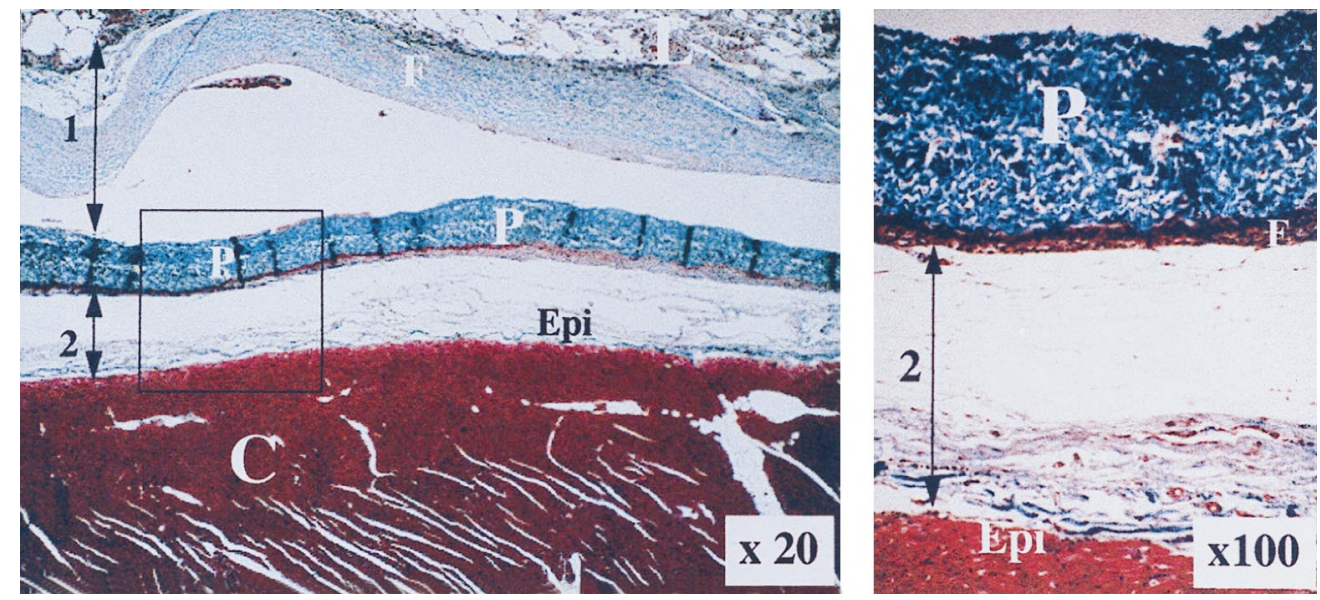

Fig. 3. The glutaraldehyde-fixed patch with ionically bound heparin retrieved 12 weeks after implantation; stain: van Gieson stain. Mild fibrosis was demonstrated with dense collagenous fibrosa $(F)$ on the epicardial surface (epi) of the patch $(P)$. Right, $\times 20$; left, $\times 100$. C, Myocardium; L, lung.
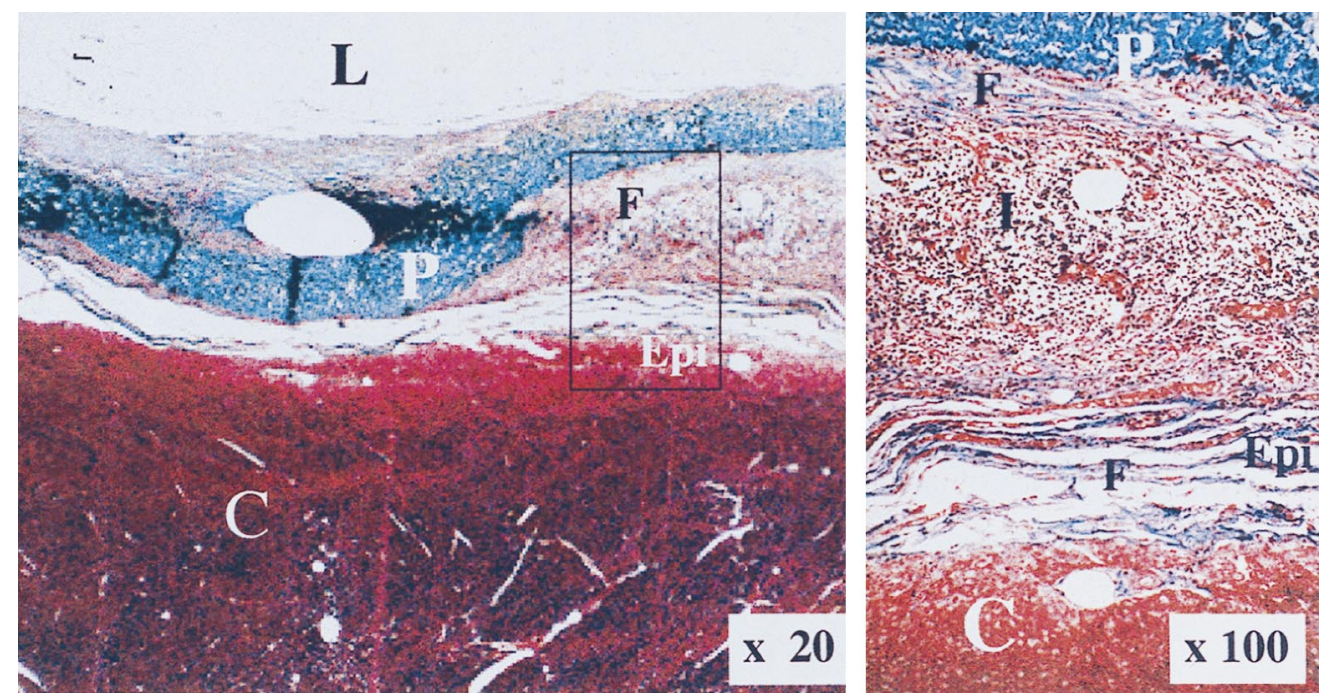

Fig. 4. The glutaraldehyde-fixed patch without ionically bound heparin retrieved 12 weeks after implantation; stain: van Gieson stain. Compared with the heparinized patch in Fig. 3, both the inflammatory (I) and fibrous reaction $(F)$ were more severe in the nonheparinized patch. Left, $\times 20$; right, $\times 100$.

macroscopically with regard to pliability of the patch, adhesions to the epicardium, and epicardial fibrous reaction (Tables III and IV). Microscopic evaluation included acute and chronic active inflammatory reaction and fibrous reaction (Tables $\mathrm{V}$ and VI).

Macroscopic findings. The synthetic patches were thicker and less pliable than the porcine pericardial patches. Additionally, the synthetic patches had a more notable adhesion and fibrosis than the biologic patches. The epicardial surface beneath all synthetic patches became thickened by a dense layer of fibrotic tissue by 12 weeks (Table III). The recognition of the coronary artery and other underlying structures beneath synthetic patches was greatly impeded by fibrotic ingrowth tissue. In this study, the smooth side of the biologic patch was in contact with the epicardial surface of the recipient heart. Generally, for all the porcine pericardial patches, the adhesion on the rough surface (pleural 

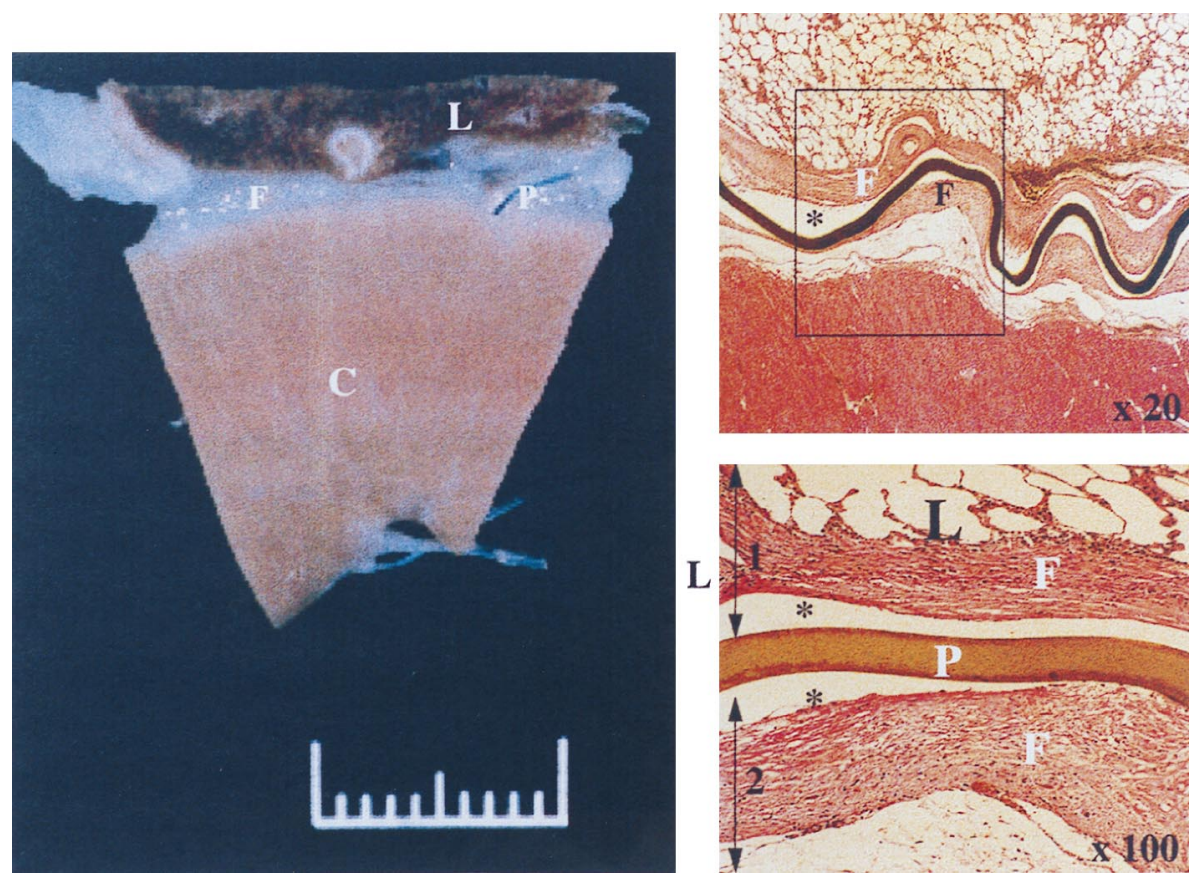

Fig. 5. An ePTFE patch retrieved 12 weeks after the operation; stain: hematoxylin-eosin. Left, On gross examination, dense adhesions with a thick layer of fibrous tissue $(F)$ were present in both sides of the patch $(P)$. The ePTFE patch did not appear shrunken or thickened. Top right, The pleural (1) and epicardial surfaces (2) were thickened. The ePTFE patch itself was intact without fibrous ingrowth. The presence of a tissue-free space $(*)$ around the ePTFE patch $(P)$ could be identified $(\times 20)$. Bottom right, Histologically, the patch was composed of hyaline and dense fibrous connective tissue. The underlying epicardium (epi) was covered by a dense layer of fibrotic tissue $(F)$ beneath the ePTFE patch $(\times 100)$.
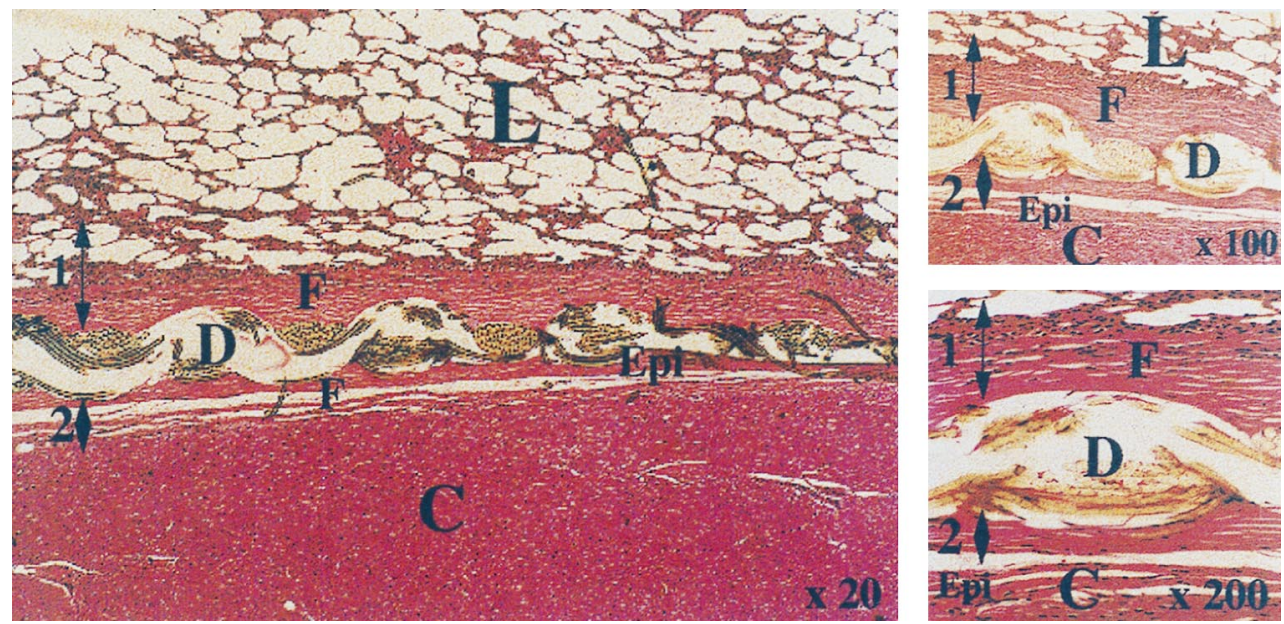

Fig. 6. A polyester patch (Dacron) retrieved 12 weeks after implantation; stain: hematoxylin-eosin. Left, On gross examination, dense adhesion with a thick layer of fibrous tissue $(F)$ was present in both sides of the Dacron patch $(D)(\times 20)$. Top right, The Dacron $(D)$ itself appeared shrunken and thickened with a dense fibrous ingrowth $(F)$. Dense adhesions were present between the inflammatory zone of pleural $(\leftrightarrow)$ and epicardial side $(\leftrightarrow)(\times 100)$. Bottom right, Severe fibrosis was identified $(\times 200)$. L, Lung; C, myocardium; Epi, epicardial fibrosis. 
side) was more severe than that observed on the smooth surface (epicardial side) (Table IV). In all groups, no differences in the formation of adhesions were noted between interrupted sutures. The adhesions were somewhat firmer at the level of suture lines.

Microscopic findings. The acute inflammatory reaction was chiefly noted in the first several weeks. This reaction consisted of ecchymosis with neutrophil infiltration into the epicardium as a sign of postoperative mechanical stimulation from a foreign body. The degree of acute inflammatory reaction decreased after 2 weeks of implantation. The chronic active inflammatory reaction consisted of a large amount of lymphocyte aggregation, histiocytes, macrophages, giant cells, and an association with necrotic cells. The fibroblast reaction was represented as focal fibrosis, hyalinization, fibrin deposit, and dense fibrous connective tissue. The severity of mononuclear lymphocyte infiltration with fibrosis as a sign of chronic active inflammatory reaction gradually increased after 4 weeks of implantation (Tables V and VI). Compatible with macroscopic findings, the inflammatory and fibrous reaction on the rough surface of biologic patch (pleural side) was more severe than that observed on the smooth surface (epicardial side).

Epoxy-fixed pericardial substitutes. On gross examination, all epoxy-fixed patches appeared soft and pliable. The patches with heparin caused minimal to mild acute and chronic inflammatory reaction between the patch and the epicardial surface before 12 weeks. Histologic studies showed only sparse neutrophils and plasma cell infiltration. Also, on gross examination, the external (pulmonic) layer of the patch showed trivial fibrin deposits. The fibrous reaction was minimal, and only scanty adhesion with fibrin deposits to the epicardium and suture lines was observed before 12 weeks. However, the adhesion was aggravated in those patches retrieved at 12 weeks. Histologic studies showed a thin fibrous tissue layer. There were mild chronic inflammatory reactions in the patches with heparin at 12 weeks after implantation (Fig. 1). Observations in the patches without heparin were similar to those in the heparin-bound patches, although the inflammatory reaction and epicardial adhesion were more severe (Fig. 2).

Glutaraldehyde-fixed pericardial substitutes. Observations in the glutaraldehyde-fixed pericardial substitutes were similar to those in their epoxy-fixed counterparts. Histologic studies showed mildly acute and chronic inflammatory reactions with focal fibrosis, a scattering of hemorrhagic infiltrates, and occasional inflammatory cells in those heparinbound patches (Fig. 3). The epicardial layer of the patch showed fibrin deposits, but they could be detached easily by finger dissection. For the patches without ionically bound heparin, adhesions had become severe at 12 weeks (Fig. 4). On the other hand, only moderate adhesions were observed for the patches with ionically bound heparin.

ePTFE pericardial substitutes. The ePTFE patch was thicker and less pliable than the porcine pericardial patches. It was adherent to the epicardial surface of the heart in all dogs at 12 weeks. On gross examination, a thick layer of fibrous tissue covering the intact patch was noted (Fig. 5, left). Dense adhesions were present between the pericardium and the myocardium. The presence of a tissue-free space around the synthetic patch can be identified in all specimen (Fig. 5, top left and bottom left). However, beneath the synthetic patch the underlying epicardium became covered by a dense layer of fibrotic tissue. The epicardial surface thickened. Recognition of the coronary artery was greatly impeded by this fibrotic tissue, which was very difficult to separate from the underlying myocardium and vessels. No ePTFE patches appeared shrunken or thickened.

Severe epicardial inflammatory reactions were present in all the test samples. At 2 weeks after implantation, moderate acute inflammatory changes with mild adhesions were observed for the ePTFE patches. These had progressed to severe adhesions with chronic active inflammatory changes at 12 weeks. The pulmonary side had a more obvious inflammatory reaction than the cardiac side in each observation. The fibrotic tissue became thicker with time. Histologically, this was composed of hyaline and dense fibrous connective tissue and showed no evidence of fibrous ingrowth.

Polyester pericardial substitutes. The polyester patch (Dacron) brought on the most severe inflammatory reaction and fibrosis between the pleura and epicardium. Diffuse fibrosis was present in all Dacron patches. On gross examination all patches appeared shrunken and thickened (Fig. 6, left). Two weeks after implantation, moderate adhesions were observed for these polyester patches. Severe adhesions were found at 4 weeks. These structural changes occurred on both surfaces of the patch (Tables IV and V). This layer could not be dissected away from the epicardium because of its thickness 
and adherence. There was no tissue-free space around the Dacron patch. The underlying structures were not identifiable. Histologic examination showed growth of dense fibrous connective tissue. The Dacron fabric itself showed a dense fibrous ingrowth of native collagen between the fiber of the Dacron patch at the sites of contact with the epicardial wall. The epicardial surface showed severe active chronic inflammation at 12 weeks (Fig. 6, top left and bottom left), which was localized directly below the patch.

\section{Discussion}

Reoperation is a risk predominantly because fibrosis and scarring increase the danger of injury to the heart, great vessels, or grafts during a repeat sternotomy. ${ }^{15}$ Reoperations are prolonged by the takedown of adhesions and are associated with increased operative bleeding and complications. The presence of epicardial fibrosis obscures the underlying anatomic structures. This is particularly important in patients undergoing repeat coronary artery revascularization, because the identification of the coronary arteries is tedious and hazardous.

Research on heterologous pericardial substitutes had focused on the glutaraldehyde-treated pericardium. Meus and coworkers ${ }^{5}$ reported that glutaraldehyde-treated biologic patches were excellent substitutes and had better antithrombogenicity than synthetic pericardial substitutes. Using a growing rat model, Okoshi's group ${ }^{16}$ reported that the epoxy-fixed collagen gel disks implanted subcutaneously showed remarkably less calcium deposition than their glutaraldehyde-fixed counterparts. To overcome the thrombogenic problem commonly observed in the prosthetic vascular grafts, Noishiki and Miyata ${ }^{14}$ developed a simple method to ionically bind heparin to the biologic arteries fixed with glutaraldehyde or epoxy compounds. In their animal studies, they found that the heparinized vascular grafts were significantly superior in antithrombogenicity to their nonheparinized counterparts. Although heparinized biomaterials, such as cardiac valve substitutes, ${ }^{16,17}$ vascular grafts, or conduits, ${ }^{18,19}$ have been throughly examined, no reports on these biomaterials in use as pericardial substitutes have been published. Inspired by these encouraging results, we undertook the development of a pericardial patch fixed in different compounds with or without ionically bound heparin.
In the development of biologic pericardial substitutes, ${ }^{12}$ it was discovered that the porcine pericardia fixed with an epoxy compound were softer and more pliable that those preserved with glutaraldehyde. Additionally, the pericardia crosslinked with polyepoxy compound appeared whiter and more appealing than their glutaraldehyde counterparts. The superiority in pliability of the pericardia fixed with epoxy compound might be due to the flexible ether joint in the epoxy compound. ${ }^{16}$ The experimental results of porcine pericardia with heparinization used to close pericardial defects in dogs are very encouraging. The porcine patches with ionically bound heparin were found to have significantly less adhesion formation than those without ionically bound heparin at each time period assessed. Although minimal adhesions developed in heparinized patches, these were easily dissected. At retrieval, under microscopic observation, minimal chronic active inflammatory changes were observed in the polyepoxy compound-cross-linked patches in comparison with their glutaraldehyde counterparts. Both ePTFE and polyester polymeric patches caused severe epicardial fibrotic adhesion with chronic active inflammatory reactions.

Overall, this observation highlighted the fact that pericardial substitutes bonded with heparin may reduce inflammatory reaction and fibrous formation. However, it is possible that the experimental findings might not be completely reproducible clinically, because the operations performed in this study did not damage the epicardium, cardiopulmonary bypass was not performed, and postoperative bleeding was minimal. The actual clinical condition might be quite different from the study design. Another unsolved problem is that the reduction of heparin on the surface of biologic tissue can reduce its antiadhesive capability. Our results suggested that a small amount of heparin was continuously released over a long period of time. Noishiki and Miyata $^{14}$ showed that about $45 \%$ of the initial heparin content was released after 1 month's rinsing in vitro, $63 \%$ after 2 months, and $76 \%$ after 3 months. In this experiment, the adhesion and fibrosis in patches with heparin are progressively increased at 12 weeks. The release rate of heparin in the pericardial substitutes with ionically bound heparin was unknown. Experiments in vitro with a longer follow-up are underway to clarify the release rate of the ionically bound heparin in pericardial substitutes. 


\section{REFERENCES}

1. Kohanna FH, Adams PX, Cunningham JN Jr, Spencer FC. Use of autologous fascia lata as a pericardial substitute following open-heart surgery. J Thorac Cardiovasc Surg 1977;74:14-9.

2. Bonnabeau RC Jr, Armanious AW, Tarnay TJ. Partial replacement of pericardium with dura substitute. J Thorac Cardiovasc Surg 1973;66:196-201.

3. Laks H, Hammond G, Geha AS. Use of silicone rubber as a pericardial substitute to facilitate reoperation in cardiac surgery. J Thorac Cardiovasc Surg 1981;80:88-92.

4. Youmans CR Jr, White J, Derrick JR. The prevention of pleural and pericardial adhesion with Silastic. J Thorac Cardiovasc Surg 1968;55:383-8.

5. Meus PJ, Wernly JA, Campell CD, Takanashi Y, Pick RL, Qui Z-K, Replogle RL. Long-term evaluation of pericardial substitutes. J Thorac Cardiovasc Surg 1983;85:54-8.

6. Gallo I, Artinano E, Duran CG. Late clinical results with the use of heterologous pericardium for closure of the pericardial cavity. J Thorac Cardiovasc Surg 1985;89:709-12.

7. von Segesser L, Jornold N, Faidutti B. Repeat sternotomy after reconstruction of the pericardial sac with glutaraldehyde-preserved equine pericardium. J Thorac Cardiovasc Surg 1987;93:616-9.

8. Skinner JR, Hyunchul K, Toon TS, Kongtahworn C, Phillips SJ, Zeff RH. Inflammatory epicardial reaction to processed bovine pericardium: case report. J Thorac Cardiovasc Surg 1984;88:789-91.

9. Inglis AE, Richter RC, Alonso DR, Gay WA, Ionescu MI. Glutaraldehyde-preserved bovine pericardial allografts for pericardial closure. J Surg Res 1984;36:50-4.

10. Mills SA. Complications associated with the use of heterol- ogous pericardium for pericardial closure. J Thorac Cardiovasc Surg 1986;92:446-54.

11. Speer DP, Chvapil M, Eskelson CD, Ulreich J. Biological effects of residual glutaraldehyde in glutaraldehyde-tanned collagen biomaterials. J Biomed Mater Res 1980;14:753-64.

12. Sung HW, Chang Y, Chiu YT, Hsu HL, et al. Evaluation of an epoxy-fixed biological patch with ionically bound heparin as a pericardial substitute. Biomaterials 1996;17: 1693-701.

13. Noishiki Y, Kodaira K, Furuse M, Miyata T. Method of preparing antithrombogenic medical materials. US Pattern 4, 805,599, 21 Feb 1989.

14. Noishiki Y, Miyata T. A simple method to heparinize biological materials. J Biomed Mater Res 1986;20:337-46.

15. Milgalter E, Uretzky G, Siberman S, et al. Pericardial meshing: an effective method for preservation of pericardial adhesions and epicardial reaction after cardiac operation. J Thorac Cardiovasc Surg 1985;90:281-6.

16. Okoshi T, Noishiki Y, Tomizawa Y, et al. A new bioprosthetic cardiac valve with reduced calcification. ASAIO J 1990;36:411-4.

17. Sung HW, Shen SH, Tu R, et al. Comparison of the cross-linking characteristics of porcine heart valves fixed with glutaraldehyde or epoxy compounds. ASAIO J 1992;39:532-6.

18. Lohre JM, Baclig L, Wickham E, et al. Evaluation of epoxy ether fixed bovine arterial grafts for mutagenic potential. ASAIO J 1993;39:106-13.

19. Xi T, Liu F, Xi B. Effect of pretreatment with epoxy compounds on the mechanical properties of bovine pericardial bioprosthetic materials. J Biomat Appl 1992;7:61-75. 